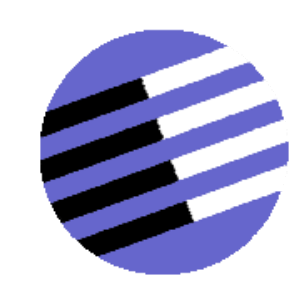

GOVERNANCE AND THE EFFICIENCY

OF ECONOMIC SYSTEMS

GESY

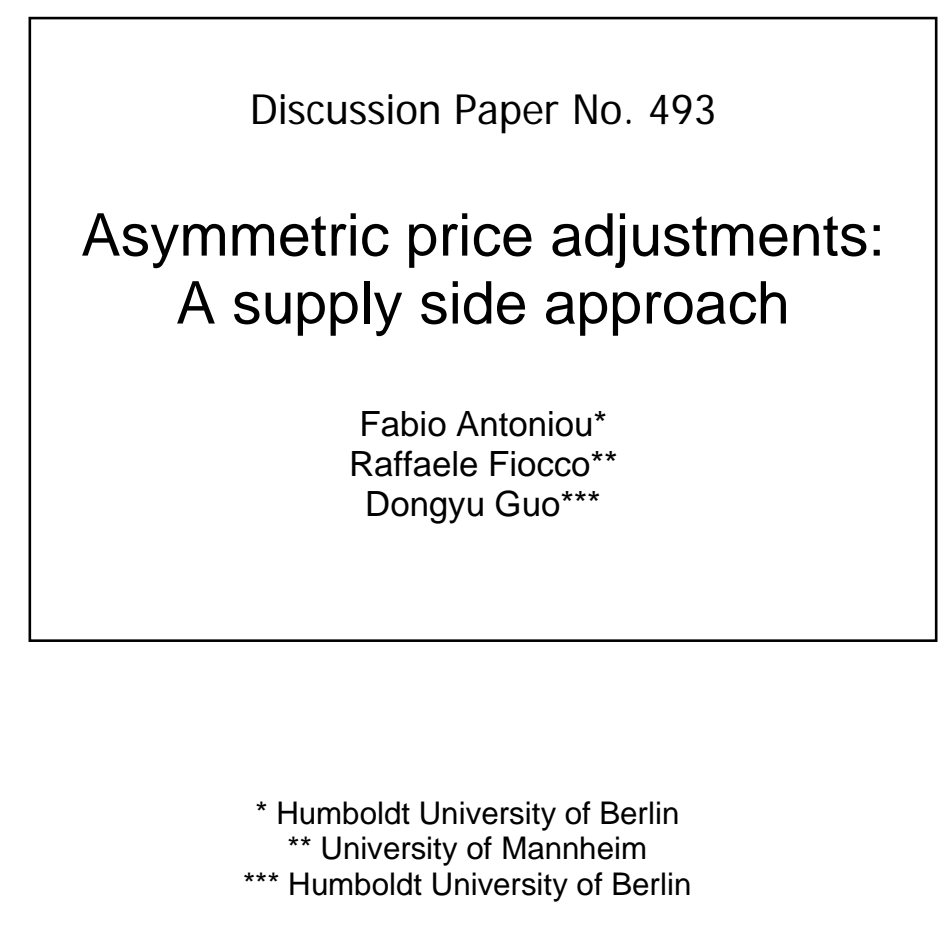

Financial support from the Deutsche Forschungsgemeinschaft through SFB/TR 15 is gratefully acknowledged.

Sonderforschungsbereich/Transregio $15 \cdot$ www.sfbtr15.de

Universität Mannheim · Freie Universität Berlin · Humboldt-Universität zu Berlin · Ludwig-Maximilians-Universität München Rheinische Friedrich-Wilhelms-Universität Bonn · Zentrum für Europäische Wirtschaftsforschung Mannheim

Speaker: Prof. Dr. Klaus M. Schmidt - Department of Economics · University of Munich · D-80539 Munich, Phone: +49(89)21802250- Fax: +49(89)21803510 


\title{
Asymmetric price adjustments: A supply side approach
}

\author{
Fabio Antoniou* Raffaele Fiocco ${ }^{\dagger} \quad$ Dongyu Guo $^{\ddagger}$
}

\begin{abstract}
Using a model of dynamic price competition, this paper provides an explanation from the supply side for the well-established observation that retail prices adjust faster when input costs rise than when they fall. The opportunity of profitable storing for the next period induces competitive firms to immediately increase their prices in anticipation of higher future input costs. This relaxes competition and firms earn positive profits. Conversely, when input costs are expected to decline, firms adjust their prices only after a cost reduction materializes, and the firms' incentives for price undercutting lead to the standard Bertrand outcome.
\end{abstract}

Keywords: Asymmetric price adjustments, Bertrand-Edgeworth competition, Storage, Gasoline market.

JEL Classification: D4, L1.

\footnotetext{
*Institute for Economic Theory I, Humboldt University of Berlin, Spandauer Str. 1, D-10178 Berlin, Germany. Email address: fabio.antoniou@wiwi.hu-berlin.de

${ }^{\dagger}$ Department of Economics, University of Mannheim, L7, 3-5, D-68131 Mannheim, Germany. Email address: raffaele.fiocco@uni-mannheim.de

${ }^{\ddagger}$ Institute for Economic Theory I, Humboldt University of Berlin, Spandauer Str. 1, D-10178 Berlin, Germany. Email address: dongyu.guo.1@hu-berlin.de
} 


\section{Introduction}

A common observation in several markets is that retail prices react asymmetrically over time in response to changes in the input prices. In particular, if the input price tends to increase, the price for the final commodity reacts immediately. However, if the input price falls, the adjustment of the retail price is slower. A well-known example that corroborates this observation is the gasoline market. ${ }^{1}$

The economic literature provides systematic empirical support for the phenomenon of asymmetric price adjustments, which is also known as rockets and feathers (e.g., Asplund et al. 2000; Bacon 1991; Blair and Rezek 2008; Borenstein et al. 1997; Chen et al. 2008; Deltas 2008; Green et al. 2010; Hannan and Berger 1991; Peltzman 2000; Valadkhani 2013; Verlinda 2008). Peltzman (2000, p. 466) emphasizes that "output prices tend to respond faster to input increases than to decreases. This tendency is found in more than two of every three markets examined."

Asymmetric price adjustments have been repeatedly associated with the collusive behavior of firms. For instance, gasoline markets can be inclined to collusion since outputs and prices are easily observable by everyone. However, as Peltzman (2000) points out, the pattern of rockets and feathers is equally likely to be found in concentrated and atomistic markets. Recently, a relevant strand of literature has focused on the idea that consumers are imperfectly informed about market prices and a fraction of them face positive search costs. Prices respond asymmetrically since consumers cannot observe current production costs and their demand is sensitive to previous cost realizations. ${ }^{2}$

In this paper we attempt to shed new light on asymmetric price adjustments in a standard competitive environment where firms provide a homogeneous good and compete in prices, abstracting from market imperfections such as collusion and limited information. The traditional economic theory suggests that firms earn zero profits and prices react symmetrically to cost shocks. Focusing on the supply side, we show that the nature of this result changes drastically if the opportunity of profitable storing is allowed.

A motivating example for our setting is the well-known shock that affected the US gasoline market in 2005 due to the hurricanes Katrina and Rita. According to the detailed investigation by the Federal Trade Commission (FTC), gas stations were selling gasoline in their tanks at significantly higher prices than actual costs and some of them earned substantial profits. The FTC found no evidence of collusion and concluded that the conduct of firms in response to the supply shocks caused by the hurricanes was consistent with competition (see FTC 2006).

We develop a two-period model where two firms sell a homogeneous good and engage in repeated Bertrand-Edgeworth competition by simultaneously setting prices and then ordering the desired quantities from their provider. A shock occurs in the economy, which makes the first period input (wholesale) costs diverge from the second period costs. In each period a firm can order a quantity up to a level that enables it to cover the whole market. Even though the possibility of price undercutting could drive prices to marginal costs, we find as a unique prediction of the game that

\footnotetext{
${ }^{1}$ Other examples can be found in the coffee, corn and banking industries.

${ }^{2}$ We refer to section 2 for a review of the relevant literature.
} 
a storage capacity leads to a prompt increase in prices above marginal costs when firms anticipate that the future input costs will be higher than the current costs. This is the case when storing for the next period is profitable, namely, when the discount factor is relatively high. The unique equilibrium price reflects the next period marginal cost, weighted by the discount factor.

The rationale behind this result is that profitable storing induces a firm to fill its depository, irrespective of what the rival does. A firm that prices at the discounted future input cost is indifferent between selling today or tomorrow and can store the purchased quantity if the rival undercuts its price and serves the market today. When input costs are expected to increase tomorrow, despite the scope for price undercutting the firms can coordinate on higher current prices than marginal costs. As a result, competition is relaxed and firms make positive profits.

It is worth emphasizing that a firm's commitment to increase its price in anticipation of higher input costs is credible as long as storing is profitable. When future discounting is relatively low and storing is unprofitable, the firms' incentives for price undercutting drive the price to the current marginal cost and the standard Bertrand outcome is restored. Consequently, prices adjust only after an increase in the input costs materializes, and the firms make zero profits.

In the same vein, when a shock is expected to decrease the input costs, storing for the next period is unprofitable and it does not serve as a commitment device. A price higher than marginal costs would drive a firm out of the market, while a price below marginal costs would entail losses. The firms are trapped in the Bertrand paradox and adjust their prices only after a cost change materializes, which yields zero profits. The opportunity of profitable storing implies that the immediate price adjustment to an input cost shock is more pronounced when the shock is positive than when it is negative. Hence, our results provide theoretical support for the phenomenon of rockets and feathers.

The driving force of our results persists in different alternative scenarios. For instance, in the baseline model we assume that the input supply is perfectly elastic and the firms cannot affect the input costs. However, in practice, input costs may also depend on the firms' demand. In a setting where input costs partially change already in the first period since the firms' higher than usual demand can only be covered at the new input cost, we find that our qualitative results remain unaffected. Storing drives asymmetric pricing even under alternative market structures, such as monopoly or Cournot competition. ${ }^{3}$ Therefore, our results provide new insights into the phenomenon of asymmetric pricing which lend themselves to a validation from the empirical or experimental literature.

\section{Related literature}

The phenomenon of asymmetric price adjustments has been explored in the economic literature which provides alternative explanations. Using panel data on US sales volume and prices of gasoline, Borestein and Shepard (1996) find evidence that the gasoline market is characterized by asymmetric

\footnotetext{
${ }^{3}$ We refer to section 7 for a discussion on the robustness of our results.
} 
price patterns and the firms' behavior is consistent with tacit collusion. A more recent strand of literature focuses on competitive environments, where consumers cannot perfectly observe market prices and search is costly. The main contributions differ in the driving force of asymmetric price adjustments and in the empirical predictions. Tappata (2009) considers a non-sequential search model with symmetric learning, while Yang and Ye (2008) provide an explanation for asymmetric pricing based on asymmetric learning by consumers. Arguing that previous work is not able to capture the specific patterns of price adjustments and of consumer search observed in retail gasoline markets, Lewis (2011) develops a search model which assumes that consumers' price expectations are based on prices observed during previous purchases. Cabral and Fishman (2012) investigate asymmetric price adjustments in a model where agents are inattentive to new information most of the time and only update their information at pre-specified intervals. As discussed in the introduction, our paper attempts to provide novel insights into the well-established phenomenon of asymmetric pricing, focusing on the supply side in a standard model that abstracts from market imperfections, such as collusion or limited information, and from behavioral aspects regarding the consumers.

Our analysis is also related to the literature on the role of inventories in the decisions of a firm. Particular attention has been devoted to the importance of inventory adjustments as a means to smooth the effects of shocks over time (e.g., Amihud and Mendelson 1983; Borenstein and Shepard 2002; Reagan 1982; Reagan and Weitzman 1982). In this paper, we emphasize the role of inventories as a driver of the asymmetric price response to input cost shocks.

The rest of the paper is organized as follows. Section 3 describes the retail gasoline market in the US, whose main features are in line with our setting. Section 4 sets out the formal model. Section 5 derives the main results. Section 6 extends our model. Section 7 discusses the robustness of our results. Section 8 concludes. All formal proofs are relegated to the Appendix.

\section{The US retail gasoline market}

Although we do not aim at explicitly modeling the retail gasoline market, our setting reflects some relevant features of this market. In the US an estimated $80 \%$ of fuel is currently sold by relatively small retail outlets and their dominance continues to grow. The majority of these firms are singlestore operators - more than 70,000 stores across the country. Half of the retail outlets sell fuel under the brand of a refining company, but virtually all of them are operated by independent entrepreneurs. The remaining half sell unbranded fuel, which is purchased on the open market or via unbranded contracts with a refiner or distributor. A station usually obtains gasoline either directly at a terminal price known as the 'rack' price or through an intermediate supplier called a 'jobber', which typically charges a competitive margin over the rack price. ${ }^{4}$

Retail gasoline prices are publicly observable and in some states (e.g., New Jersey and Wisconsin) consumer protection laws require that posted gasoline prices remain in effect at least for a

\footnotetext{
${ }^{4}$ The interested reader is referred to the NACS Retail Fuels Report of the Association for Convenience and Fuel Retailing available at www.nacsonline.com/YourBusiness/FuelsReports/Pages/default.aspx.
} 
given period, generally 24 hours. Since gasoline evaporates rather quickly, carrying large quantities is suboptimal. Moreover, the size of tanks in gas stations is limited by physical constraints. The report of the economist Keith Leffler (2007, p. 33), which investigates the factors that influence regional gas prices throughout the state of Washington, states that "the inventory philosophy of producers is 'just in time' to have adequate supplies to meet expected demand. Only two to five days of finished product is available to bridge short-term supply interruptions."

When setting the prices and ordering the quantities from their providers, the retailers generally face the rack price (plus a competitive distribution margin) as a marginal cost. If unexpected events occur which affect the import or refining stage (say, a conflict in an oil-producing country or a hurricane), rack prices may increase immediately and, more relevantly, they are expected to rise even more in the near future due to possible supply shortages. In particular, as described in the NACS Retail Fuels Report of the Association for Convenience and Fuel Retailing (2013, p. 63), "when disruptions occur, retailers [...] are susceptible to changes in product availability and volatile wholesale prices. Branded fuel retailers may incur price increases and be put on volume allocations. Meanwhile, unbranded retailers may experience more dramatic wholesale price increases, since they must compete for limited supply on the spot market, or be denied access to supplies completely."

\section{The model}

\subsection{Setting}

We consider two symmetric firms $i=1,2$ that provide a homogeneous good and engage in repeated Bertrand-Edgeworth competition by simultaneously deciding on their prices and then on their output levels, which is known in the literature as production to order (e.g., Chowdhury 2005; Dixon 1984; Maskin 1986). As discussed in section 7, our qualitative results go through when prices and quantities are set simultaneously. ${ }^{5}$ In each period $\tau=1$, 2 , firm $i$ sets a price $p_{\tau i}$ for the good and then orders a quantity $q_{\tau i}$ from its provider. We denote by $q_{\tau i}^{m}$ the quantity that firm $i$ places on the market in period $\tau$. Since we aim at analyzing short-term events, we assume that market demand is inelastic and in each period consumers purchase a quantity $d>0$ irrespective of the price level. ${ }^{6}$ Following the relevant literature (see Chowdhury 2005 and the references cited therein), the residual demand for firm $i$ is given by

$$
R_{\tau i}\left(p_{\tau i}, p_{\tau j}, q_{\tau j}^{m}\right)= \begin{cases}d-q_{\tau j}^{m} & \text { if } p_{\tau i}>p_{\tau j} \\ \max \left\{\frac{d}{2}, d-q_{\tau j}^{m}\right\} & \text { if } p_{\tau i}=p_{\tau j} \\ d & \text { if } p_{\tau i}<p_{\tau j}\end{cases}
$$

\footnotetext{
${ }^{5}$ We refer to Allen and Hellwig (1986), Dasgupta and Maskin (1986), Dixon (1984) and Maskin (1986) for an analysis of equilibrium existence in Bertrand-Edgeworth models. More recently, Chowdhury (2009) investigates a model of Bertrand competition in the presence of non-rigid capacity constraints.

${ }^{6}$ Inelastic demand seems to be a reasonable assumption in the gasoline retail market, where consumer demand is largely unresponsive to changes in prices at least in the short run. In section 7 we argue that our qualitative results go through with more general demand functions.
} 
The residual demand in (1) is distributed according to the efficient rationing rule. As long as the demand is inelastic, this formulation captures any combined rationing rule, including the proportional rationing rule (e.g., Tasnádi 1999). The second line of equation (1) identifies the tie-breaking rule that is used, among others, in Davidson and Deneckere (1986) and Kreps and Scheinkman (1983). This formulation exhibits the attractive feature that it allows for the spillover of the uncovered residual demand from one firm to another. ${ }^{7}$

The quantity $q_{\tau i}$ that firm $i$ orders in each period cannot exceed $d$, which represents the firm's storage capacity. ${ }^{8}$ This assumption is reasonable in markets where storing large quantities is unfeasible. For instance, as argued in section 3, gasoline evaporates quite quickly and the size of tanks in gas stations is limited by physical constraints. In section 7 we show that our qualitative results carry over with alternative storage capacities. Notably, a storage capacity equal to $d$ allows each firm to serve the whole market, and the possibility of price undercutting could drive prices to marginal costs.

Each period $\tau$ firm $i$ may store (a part of) the ordered quantity $q_{\tau i}$ for the next period. Let $q_{\tau i}^{r}$ be the quantity that firm $i$ stores in period $\tau$ for the period $\tau+1$, namely, firm $i$ 's reserves. The firms incur a constant $\operatorname{cost} c_{\tau}$ per unit of input (e.g., the rack price for gasoline) in period $\tau$.

Firm $i$ 's profits in period $\tau$ are given by

$$
\pi_{\tau i}=p_{\tau i} \min \left\{q_{\tau i}^{m}, R_{\tau i}\left(p_{\tau i}, p_{\tau j}, q_{\tau j}^{m}\right)\right\}-c_{\tau} q_{\tau i}, \quad \tau, i=1,2
$$

which represents the difference between total revenues and total costs. Total revenues depend on the quantity sold on the market. Since we allow for voluntary trading, this quantity is the minimum between the quantity that the firm puts on the market and the firm's residual demand in (1). ${ }^{9}$ The firm's total costs depend on the quantity ordered.

Firm $i$ 's aggregate profits can be written as

$$
\pi_{i}=\pi_{1 i}+\delta \pi_{2 i}
$$

where $\delta \in(0,1]$ is the discount factor on the second period.

\subsection{Input cost shock}

As discussed in the introduction, our purpose is to investigate a situation where a shock occurs in the input market which makes the current input costs diverge from the future costs. If the shock is positive, input costs tend to increase, i.e., $c_{2}>c_{1}$. This is typically the case after extreme weather phenomena or the exacerbation of political instability in an oil-producing country, which can lead to supply disruptions. If the shock is negative, such as the sudden end of a conflict in an oil-producing country or the announcement of the US Department of Energy that the strategic

\footnotetext{
${ }^{7}$ Our results carry over with alternative tie-breaking rules, such as $R_{\tau i}=d \frac{q_{\tau i}^{m}}{q_{\tau i}^{m}+q_{\tau j}^{m}}\left(\right.$ for $q_{\tau i}^{m}+q_{\tau j}^{m}=0$, this tiebreaking rule becomes $R_{\tau i}=\frac{d}{2}$ ).

${ }^{8} \mathrm{We}$ assume that storage is costless. Introducing a positive cost of storage does not alter our qualitative results.

${ }^{9}$ Nothing substantial would change if the firms must fully cover the consumer demand.
} 
oil inventories have increased, then input costs tend to decrease, i.e., $c_{2}<c_{1}$. For the sake of simplicity, we assume that input costs vary in a deterministic way, but our results carry over even with cost uncertainty as long as the firms expect that future costs will depart from current costs.

In the baseline model we suppose that the input supply is perfectly elastic in every period. Since in practice retailers may affect input prices through their demand, in section 6 we consider a situation where input costs partially change already in the first period since the retailers' higher than usual demand can only be satisfied at the new input cost.

\subsection{Timing and equilibrium concept}

The timing of the model unfolds as follows.

\section{First period}

(I) Cost $c_{1}$ is realized.

(II) The firms simultaneously set their prices.

(III) The firms simultaneously order the quantities that are sold on the market or stored in the depository for the next period.

\section{Second period}

(IV) Cost $c_{2}$ is realized.

(V) The first period competition stages (II) and (III) are repeated.

The equilibrium concept we adopt is the Subgame Perfect Nash Equilibrium (SPNE). ${ }^{10}$ Moving backwards, we first derive the equilibrium prices and quantities in the second period. Afterwards, we determine the first period outcome of the game and derive the corresponding equilibrium prices and quantities.

\section{Main results}

\subsection{Second period equilibrium}

The following lemma characterizes the equilibrium prices and quantities in the second period.

Lemma 1 A. If $\sum_{i=1}^{2} q_{1 i}^{r} \leq d$, the outcome $\left(p_{2 i}^{*}, q_{2 i}^{m *}, q_{2 i}^{r *}\right)$ constitutes an equilibrium of the second period continuation game if and only if $p_{2 i}^{*}=c_{2}, \sum_{i=1}^{2} q_{2 i}^{m *} \leq d$ and $q_{2 i}^{r *}=0, i=1,2$.

B. If $\sum_{i=1}^{2} q_{1 i}^{r}>d$, the outcome $\left(p_{2 i}^{*}, q_{2 i}^{m *}, q_{2 i}^{r *}\right)$ constitutes an equilibrium of the second period continuation game if and only if $p_{2 i}^{*} \in\left[\underline{p}_{2}^{*}, \bar{p}_{2}^{*}\right] \subseteq\left[0, c_{2}\right], \sum_{i=1}^{2} q_{2 i}^{m *}=d$ and $q_{2 i}^{r *}=\max \left\{0, q_{1 i}^{r *}-q_{2 i}^{m *}\right\}$, $i=1,2$.

\footnotetext{
${ }^{10}$ In line with the main literature we allow for mixed strategies but look for SPNE without mixing on the equilibrium path.
} 
Lemma 1A indicates that, if the total amount of reserves from the first period does not exceed the demand $d$, the equilibrium price in the second period reflects the current marginal cost $c_{2}$. This holds true even though the cost of reserves was incurred in the first period and it is therefore zero in the second period. A price higher than the marginal cost clearly drives a firm out of the market. No firm has an incentive to set a price below the marginal cost, since it cannot undercut the rival's price and profitably sell more than its reserves. Moreover, since we allow for voluntary trading, in equilibrium a part of the market may remain uncovered, yet the reserves are fully exhausted.

As Lemma 1B reveals, things are different when the aggregate reserves are greater than the demand. Since the market cannot absorb all the reserves and their cost was sunk in the first period, a price war takes place between the firms as they try to sell their reserves. Following Levitan and Shubik (1972) and Osborne and Pitchik (1986), there exists a (generally unique) mixed

strategy equilibrium where firms randomize in prices within the interval $\left[\underline{p}_{2}^{*}, \bar{p}_{2}^{*}\right] \subseteq\left[0, c_{2}\right]$. Any price above $c_{2}$ cannot be set with positive probability, since the standard undercutting rationale applies. Contrary to the case where the total amount of reserves does not exceed the demand, choosing with probability 1 a price equal to the marginal cost cannot be sustained as an equilibrium, since each firm has an incentive to undercut the rival and sell off all its reserves. The lower bound of the price interval crucially depends on the amount of reserves. If either firm does not carry full reserves, i.e., $\sum_{i=1}^{2} q_{1 i}^{r} \in(d, 2 d)$, the minimum price is strictly above zero since (at least) the firm with lower reserves cannot serve the whole market, which mitigates the incentives to undercut. Only if both firms carry full reserves, i.e., $q_{1 i}^{r}=d, i=1,2$, can each firm undercut the rival and serve the whole market, which drives the price to zero. The market demand is always satisfied through the reserves.

An implication of Lemma 1, which is useful throughout the rest of the analysis, is that the second period equilibrium price can never exceed the current input cost $c_{2}$, irrespective of what occurred in the first period.

\subsection{Benchmark case: No shock}

For illustrative purposes we first consider the benchmark case where no shock occurs, i.e., $c_{1}=$ $c_{2} \equiv c$. This translates into a dynamic version of the one-period game described in Chowdhury (2005) where we introduce the storing option.

The following remark summarizes the equilibrium of the game in the absence of a shock.

Remark 1 Suppose $c_{1}=c_{2} \equiv c$. Then, the outcome $\left(p_{\tau i}^{*}, q_{\tau i}^{m *}, q_{\tau i}^{r *}\right)$ constitutes a SPNE if and only if $p_{\tau i}^{*}=c$ and $\sum_{i=1}^{2} q_{\tau i}^{m *} \leq d, \tau, i=1,2$. If $\delta<1$, then $q_{\tau i}^{r *}=0, \tau, i=1,2$. If $\delta=1$, then $\sum_{i=1}^{2} q_{1 i}^{r *} \leq d$ and $q_{2 i}^{r *}=0, i=1,2$.

The opportunity of storing some quantity for the next period does not alter the outcome of the static game. The firms set a price equal to the marginal cost in each period and earn zero profits. If $\delta<1$, storing is clearly profit detrimental, since the marginal cost $c$ is higher than the second period discounted price (which is bounded above at $\delta c$, according to Lemma 1). If $\delta=1$, storing is at best not harmful and the firms cannot improve their profits. Therefore, in equilibrium the firms 
are indifferent to storing or not provided that the total amount of reserves does not exceed the demand. Otherwise, the second period price would fall below $c$ and storing would be detrimental.

\subsection{Positive shock}

For the sake of convenience, we split our analysis according to the direction of the shock in the input market. We first investigate the case of a positive shock where input costs tend to increase, i.e., $c_{2}>c_{1}$. Intuitively, a positive shock creates an incentive to purchase at a cost $c_{1}$ a quantity that is higher than usual. We know from Lemma 1 that, if the aggregate stored quantity from the first period does not exceed the demand, the second period price will be equal to the new marginal $\operatorname{cost} c_{2}$. This gives the firms the opportunity to sell at a positive margin.

The following proposition describes the equilibrium of the game in the presence of a positive shock.

Proposition 1 Suppose $c_{2}>c_{1}$.

A. If $\delta \geq \frac{c_{1}}{c_{2}}$, the outcome $\left(p_{\tau i}^{*}, q_{\tau i}^{m *}, q_{\tau i}^{r *}\right)$ constitutes a SPNE if and only if $p_{1 i}^{*}=\delta p_{2 i}^{*}=\delta c_{2}$, $\sum_{i=1}^{2} q_{\tau i}^{m *}=d, q_{1 i}^{r *}=d-q_{1 i}^{m *}$ and $q_{2 i}^{r *}=0, \tau, i=1,2$.

B. If $\delta<\frac{c_{1}}{c_{2}}$, the outcome $\left(p_{\tau i}^{*}, q_{\tau i}^{m *}, q_{\tau i}^{r *}\right)$ constitutes a SPNE if and only if $p_{\tau i}^{*}=c_{\tau}, \sum_{i=1}^{2} q_{\tau i}^{m *} \leq d$ and $q_{\tau i}^{r *}=0, \tau, i=1,2$.

Proposition $1 \mathrm{~A}$ considers the case where the discount factor $\delta$ is relatively high so that purchasing one unit of the commodity at $c_{1}$ in the first period and selling it at $c_{2}$ in the second period is profitable. Anticipating higher future input costs, the firms immediately adjust their prices at the discounted second period input cost $\delta c_{2}$. In order to substantiate the intuition behind this result as provided in the introduction, it is important to realize that for $\delta \geq \frac{c_{1}}{c_{2}}$ each firm has an incentive to purchase a quantity $d$ in the first period, which can be partially stored and profitably sold in the second period. It follows from Lemma 1 that, if the aggregate reserves do not exceed the demand, a firm that adjusts its price at $\delta c_{2}$ is indifferent between serving the market today or tomorrow. Therefore, it can credibly commit to purchase $d$ even if the rival undercuts its price. In particular, if the undercutting firm prefers to (partially) serve the market today, the non-deviating firm can store (a portion of) $d$ and sell it tomorrow at $c_{2}$. Any deviation above $\delta c_{2}$ is unprofitable as long as the firm conjectures that the rival will cover the whole market.

As described in Remark 1, in the absence of a shock each firm cannot credibly commit not to be aggressive vis-à-vis the rival, and the standard Bertrand rationale applies. When input costs are expected to increase tomorrow, profitable storage acts as a commitment device to increase prices already today, which relaxes competition. The firms can coordinate to increase prices above marginal costs and earn positive profits. Notably, Proposition 1A shows that the price at the discounted second period input cost is the unique equilibrium of the game. ${ }^{11}$ Although the market can be split between firms in several manners (the symmetric equilibrium $q_{\tau i}^{m *}=\frac{d}{2}, \tau, i=1,2$, is

\footnotetext{
${ }^{11}$ We refer to the proof of Proposition 1 in the Appendix for technical details.
} 
only one possibility among others), the market is fully covered in both periods because each firm orders and sells $d$.

Since we aim at analyzing short-term events, we expect that the discount factor will be relatively high and the outcome of Proposition 1A is the most relevant for our purposes. Proposition 1B describes what happens if the firm's future discounting is low enough, i.e., $\delta<\frac{c_{1}}{c_{2}}$. The rationale for this result is immediate in light of our previous discussion. Since storing is not profitable and cannot be used as a commitment device to relax competition, the firms are trapped in the Bertrand paradox and set their prices at the current marginal costs, which yield zero profits.

\subsection{Negative shock}

We now turn to the case of a negative shock where input costs tend to decrease, i.e., $c_{2}<c_{1}$. The following proposition summarizes the main results.

Proposition 2 Suppose $c_{2}<c_{1}$. Then, the outcome $\left(p_{\tau i}^{*}, q_{\tau i}^{m *}, q_{\tau i}^{r *}\right)$ constitutes a SPNE if and only if $p_{\tau i}^{*}=c_{\tau}, \sum_{i=1}^{2} q_{\tau i}^{m *} \leq d$ and $q_{\tau i}^{r *}=0, \tau, i=1,2$.

Proposition 2 replicates the outcome in Proposition 1B. When a shock is expected to reduce the input costs, storing is clearly unprofitable and firms cannot coordinate on prices higher than marginal costs. Moreover, any price below the current costs would entail non-positive profits. As a consequence, the price in each period reflects the current marginal cost and the standard Bertrand rationale applies.

It is worth noting that in our model the role of storing depends on the discount factor but it can be also viewed as a function of the magnitude of the shock in the input market for a given discount. An alternative interpretation of our results is that, if the magnitude of the shock is large enough (i.e., if $c_{2}$ is sufficiently higher than $c_{1}$ ), storing is profitable and the firms adjust their prices to the cost shock faster than when the shock is relatively small or even negative. The driving force of our results is the opportunity of profitable storing and, as it emerges from sections 6 and 7 , the model is robust to perturbations of the initial assumptions in different directions, as long as storing is relevant.

\subsection{Empirical implications}

We are now in a position to relate our results to the empirical predictions. In order to derive the price-cost pass-through rates over time, we introduce a pre-shock period, called period 0 , where the input cost is the same as in the first period, i.e., $c_{0}=c_{1} \cdot{ }^{12}$ Moreover, we assume that in period 0 the price reflects the current marginal cost, $p_{0}=c_{0} \cdot{ }^{13}$ Using the results in Propositions 1 and 2,

\footnotetext{
${ }^{12}$ The results remain qualitatively unaffected if the input shock also alters the cost already in the first period, i.e., $c_{0} \neq c_{1}$.

${ }^{13}$ In other terms, before the shock we are in the long-run equilibrium. This is a reasonable assumption when the future shock is unexpected, so that the firms cannot react in period 0 . Any other price-cost relationship in period 0 that differs from marginal cost pricing does not alter our qualitative conclusions.
} 


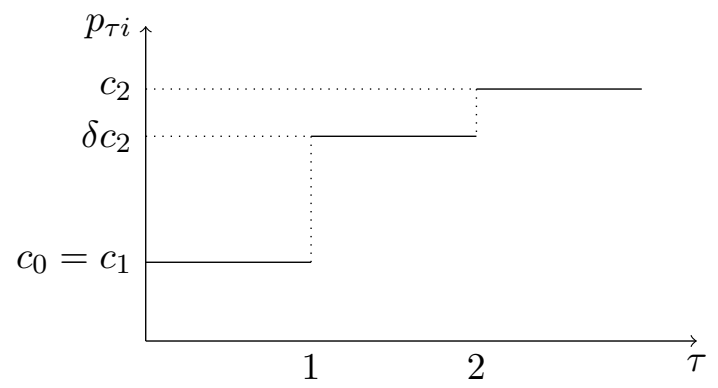

(a) Positive shock and high discount factor

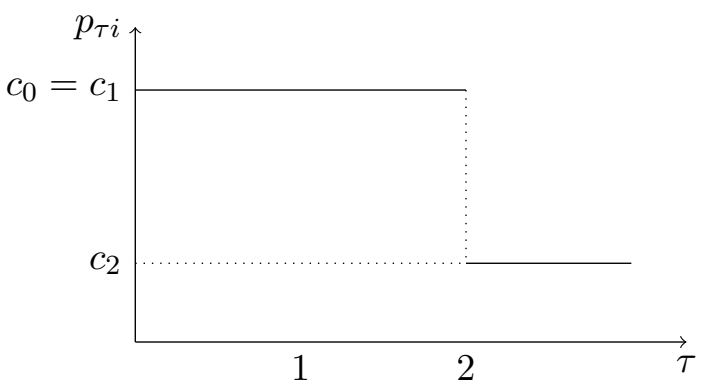

(b) Negative shock

Figure 1: Price adjustments

the percentage variations in prices following a shock are

$$
\widehat{\beta}_{0}^{+}=\frac{\delta c_{2}-c_{1}}{c_{1}}, \widehat{\beta}_{1}^{+}=\frac{1-\delta}{\delta}, \widehat{\beta}_{0}^{-}=0, \text { and } \widehat{\beta}_{1}^{-}=\frac{c_{1}-c_{2}}{c_{1}}
$$

where $\widehat{\beta}_{0}^{+}$and $\widehat{\beta}_{1}^{+}$respectively denote the percentage variations in prices between periods 0 and 1 and between periods 1 and 2 due to a positive input shock (for $\delta \geq \frac{c_{1}}{c_{2}}$ ). The interpretation of $\widehat{\beta}_{0}^{-}$ and $\widehat{\beta}_{1}^{-}$follows similarly in case of a negative shock. A comparison between $\widehat{\beta}_{0}^{+}$and $\widehat{\beta}_{0}^{-}$immediately reveals that $\widehat{\beta}_{0}^{+}>\widehat{\beta}_{0}^{-}$for $\delta>\frac{c_{1}}{c_{2}}$, namely, final prices rise faster when input costs increase than when they fall if storing is profitable. In particular, $\widehat{\beta}_{0}^{-}=0$ indicates an initial price stickiness with a negative shock. The speed of later adjustment is reversed, namely, $\widehat{\beta}_{1}^{+}<\left|\widehat{\beta}_{1}^{-}\right|$. This is in line with the main empirical literature (e.g., Borestein et al. 1997; Chesnes 2012), which shows that retail prices initially react faster when the input shock is positive but the opposite occurs when the total adjustment is near completion.

It is also worth noting from (2) that, unless $\delta=1$, the price adjustment in case of a positive shock unravels gradually. In particular, we have $\widehat{\beta}_{1}^{+}>\widehat{\beta}_{0}^{+}$if $\delta>\left(\frac{c_{1}}{c_{2}}\right)^{\frac{1}{2}}$. Put differently, when the discount factor is relatively high, the relative increase in prices is more pronounced in the first than in the second period. This is consistent with the empirical evidence that the price-cost pass-through declines over time with a positive shock.

Our results are depicted for illustrative purposes in Figure 1, where panel (a) shows the price adjustment over time in the presence of a positive shock and panel (b) indicates the price adjustment with a negative shock.

To investigate the empirical implications of our results, it is also helpful to translate them in terms of empirical models. Our predictions can be estimated via a dynamic model of the following form

$$
\Delta p_{\tau}=\sum_{i=0}^{n^{+}} \beta_{i}^{+} \Delta c_{\tau+k-i}^{+}+\sum_{i=0}^{n^{-}} \beta_{i}^{-} \Delta c_{\tau+k-i}^{-}+\varepsilon_{\tau}
$$

Equation (3) reflects the idea that the spread in retail prices $\Delta p_{\tau}$ between periods $\tau-1$ and $\tau$ depends on positive and negative cost changes $\Delta c_{\tau+k-i}^{+}$and $\Delta c_{\tau+k-i}^{-}$at possibly different rates $\beta_{i}^{+}$ 
and $\beta_{i}^{-}$, plus an error term $\varepsilon_{\tau} \cdot{ }^{14}$ The term $k \geq 0$ captures the impact of anticipated future cost changes on the current price change. For $k=0$ the econometric model in (3) is fairly standard in the empirical literature (e.g., Borenstein et al. 1997; Chesnes 2012). Positive values of $k$ indicate that an anticipated cost change between periods $\tau+k-1$ and $\tau+k$ can affect the price change already $k$ periods earlier. This is a key message of our paper for the empirical studies. The predictions of our model suggest that in markets with storing opportunities the anticipation of future cost changes is a relevant driver for asymmetric pricing.

Our aim is to derive the estimated $\beta_{i}^{+}$and $\beta_{i}^{-}$in (3) that our model generates. The phenomenon of rockets and feathers occurs if $\beta_{i}^{+}>\beta_{i}^{-}$for at least one lag $i$. We first consider the case of a positive shock, $c_{2}>c_{1}$, and a relatively high discount factor, $\delta \geq \frac{c_{1}}{c_{2}}$. Since in our stylized twoperiod model only the costs in the next period can be anticipated, i.e., $k=1$, plugging our results into (3) and neglecting the error term $\varepsilon_{\tau}$ yields after some manipulation

$$
\begin{gathered}
p_{1}-p_{0}=\delta c_{2}-c_{1}=\beta_{0}^{+}\left(c_{2}-c_{1}\right) \\
p_{2}-p_{1}=c_{2}-\delta c_{2}=\beta_{1}^{+}\left(c_{2}-c_{1}\right) .
\end{gathered}
$$

This implies $\beta_{0}^{+}=\frac{\delta c_{2}-c_{1}}{c_{2}-c_{1}}$ and $\beta_{1}^{+}=\frac{c_{2}-\delta c_{2}}{c_{2}-c_{1}}$. When the shock is negative, we find

$$
\begin{gathered}
p_{1}-p_{0}=0=\beta_{0}^{-}\left(c_{2}-c_{1}\right) \\
p_{2}-p_{1}=c_{2}-c_{1}=\beta_{1}^{-}\left(c_{2}-c_{1}\right),
\end{gathered}
$$

which yields $\beta_{0}^{-}=0$ and $\beta_{1}^{-}=1$. The predictions of our model reveal the existence of asymmetric pricing. We find for $\delta>\frac{c_{1}}{c_{2}}$ that $\beta_{0}^{+}>\beta_{0}^{-}=0$, namely, the immediate price adjustment is larger with a positive shock than with a negative shock when storing is profitable, and the negative shock is associated with a price stickiness. The speed of later adjustment is reversed, $\beta_{1}^{+}<\beta_{1}^{-}$. Moreover, we have $\sum_{i=0}^{n^{+}} \beta_{i}^{+}=\sum_{i=0}^{n^{-}} \beta_{i}^{-}$, which is consistent with the empirical evidence that in most markets the wholesale and retail prices do not tend to diverge over time.

\section{Endogenous input cost}

The results derived so far are based on the assumption that in each period the input supply is perfectly elastic. Put differently, each firm could potentially order infinite quantities at the current input costs. In reality, however, the change in the firms' demand due to a shock may affect the input costs. To investigate this case, we now assume that in the first period the (common) provider can obtain a quantity up to $d$ (which represents the 'historical' quantity, i.e., the quantity in the absence of a shock) at a cost $c_{1}$, for instance, due to long-term contracts. If the provider wants to acquire larger quantities to serve the firms' demand, it must resort to other sources (say, the spot market) and pay the new input $\operatorname{cost} c_{2}$ on the additional amount already in the first period. The

\footnotetext{
${ }^{14}$ Equation (3) may also include an error correction term that accounts for deviations from the long-run equilibrium. Neglecting this term does not affect our results qualitatively.
} 
provider's average cost function exhibits a kink at $d$, and the price charged by the provider now depends on the firms' demand for the input.

An endogenous input cost complicates the analysis, since it creates an interdependence between the firms' costs. Nonetheless, as this reflects economic realities to some extent, an investigation of such a case is warranted in order to check the robustness of the results presented in the previous section.

In light of this discussion, the average input cost in the first period is given by

$$
\widetilde{c}_{1}=\frac{c_{1} \min \left\{d, \sum_{i=1}^{2} q_{1 i}\right\}+c_{2} \max \left\{0, \sum_{i=1}^{2} q_{1 i}-d\right\}}{\sum_{i=1}^{2} q_{1 i}} .
$$

We assume that the provider sets an input price equal to the average cost in (4) plus a fixed markup (normalized to zero). This input price rule captures in a simple but effective manner the idea that the firms' demand affects the input price, abstracting from the mode of competition in the upstream market. When the firms' demand does not exceed $d$, the provider does not need to purchase any quantity from additional sources and therefore the first period input cost is $c_{1}$. If, however, the firms' demand is higher than $d$, the provider must acquire any additional quantity at $c_{2}$, which increases (decreases) the average cost in (4) if $c_{2}>(<) c_{1}$ and affects in the same direction the input cost incurred by the firms.

\subsection{Positive shock}

The following proposition considers the case of a positive shock.

Proposition 3 Suppose $c_{2}>c_{1}$.

A. If $\delta \geq \frac{1}{4}\left(3+\frac{c_{1}}{c_{2}}\right)$, the outcome $\left(p_{\tau i}^{*}, q_{\tau i}^{m *}, q_{\tau i}^{r *}\right)$ constitutes a SPNE if and only if $p_{1 i}^{*}=\delta p_{2 i}^{*}=$ $\delta c_{2}, \sum_{i=1}^{2} q_{\tau i}^{m *}=d, q_{1 i}^{r *}=d-q_{1 i}^{m *}$ and $q_{2 i}^{r *}=0, \tau, i=1,2$.

B. If $\frac{c_{1}}{c_{2}} \leq \delta<\frac{1}{4}\left(3+\frac{c_{1}}{c_{2}}\right)$, no equilibrium exists.

C. If $\delta<\frac{c_{1}}{c_{2}}$, the outcome $\left(p_{\tau i}^{*}, q_{\tau i}^{m *}, q_{\tau i}^{r *}\right)$ constitutes a SPNE if and only if $p_{\tau i}^{*}=c_{\tau}, \sum_{i=1}^{2} q_{\tau i}^{m *} \leq d$ and $q_{\tau i}^{r *}=0, \tau, i=1,2$.

Proposition $3 \mathrm{~A}$ indicates that, if the discount factor is sufficiently high, i.e., $\delta \geq \frac{1}{4}\left(3+\frac{c_{1}}{c_{2}}\right)$, the equilibrium price in the first period equals the discounted second period marginal cost $\delta c_{2}$ and reaches $c_{2}$ in the second period, which ensures that each firm is indifferent to selling across the two periods. The critical value of the discount factor, $\frac{1}{4}\left(3+\frac{c_{1}}{c_{2}}\right)$, corresponds to the threshold above which each firm orders $d$ in the first period and the demand is fully covered in each period. The intuition for this result falls across the same lines as in Proposition 1A. It is worth mentioning that the critical threshold of the discount factor is higher than in the baseline model, i.e., $\frac{1}{4}\left(3+\frac{c_{1}}{c_{2}}\right)>$ $\frac{c_{1}}{c_{2}}$. The idea is that now storing increases the firms' unit costs already in the first period, which strengthens the condition under which each firm finds it optimal to order $d$ in the first period.

Another dimension introduced by an endogenous input cost is the indeterminacy for an intermediate range of values for the discount factor, i.e., $\frac{c_{1}}{c_{2}} \leq \delta<\frac{1}{4}\left(3+\frac{c_{1}}{c_{2}}\right)$. As Proposition 3B 
reveals, in this case no equilibrium exists (in pure or in mixed strategies). To fix ideas, consider the equilibrium prices described in Proposition 3A. At these prices, since for intermediate values of the discount factor storing is still profitable but to a lower extent than in the previous case, the quantity equilibrium involves orders lower than $d$ in the first period. Following a price increase of the rival, the non-deviating firm still does not want to order $d$ and serve the whole market. This implies that a firm can (infinitely) raise its price in the first period and serve the uncovered part of the market. This conclusion differs from the result in the baseline model, where each firm has an incentive to order $d$ in the first period for $\delta \geq \frac{c_{1}}{c_{2}}$ irrespective of what the rival does, which prevents any profitable deviation. The reason is that storing now increases the firms' unit costs already in the first period, which makes storing less attractive.

Following a loose dynamic argument, as long as the first period prices are higher than $\delta c_{2}$, each firm has an incentive to undercut the rival's price in order to sell in the first period. Moreover, any price below $\delta c_{2}$ cannot be supported as an equilibrium, since the non-deviating firm would prefer to sell in the next period while the rival could increase the price and sell profitably in the first period. Hence, for $\frac{c_{1}}{c_{2}} \leq \delta<\frac{1}{4}\left(3+\frac{c_{1}}{c_{2}}\right)$, there is no equilibrium in the price setting game and therefore no SPNE exists. ${ }^{15}$

Proposition 3C predicts that, if the discount factor is low enough, i.e., $\delta<\frac{c_{1}}{c_{2}}$, storing is unprofitable and no firm has an incentive to order any quantity for the next period irrespective of what the rival does, since this would result in a net loss. Therefore, prices adjust to the current input costs as in Proposition 1B and the standard Bertrand argument applies in each period of the game.

\subsection{Negative shock}

The following proposition describes what happens in the case of a negative shock.

Proposition 4 Suppose $c_{2}<c_{1}$. Then, the outcome $\left(p_{\tau i}^{*}, q_{\tau i}^{m *}, q_{\tau i}^{r *}\right)$ constitutes a SPNE if and only if $p_{\tau i}^{*}=c_{\tau}, \sum_{i=1}^{2} q_{\tau i}^{m *} \leq d$ and $q_{\tau i}^{r *}=0, \tau, i=1,2$.

Proposition 4 replicates the outcome of Proposition 2. As in the baseline model, storing is unprofitable since the first period cost $\widetilde{c}_{1}$ is higher than the second period $\operatorname{cost} c_{2}$. However, deriving the equilibrium is now more demanding as $\widetilde{c}_{1}$ might be lower than $c_{1}$ in equilibrium. This would be the case if the aggregate orders in the first period are higher than $d$. Things become more complicated since it is not straightforward to see whether price undercutting below $c_{1}$ in the

\footnotetext{
${ }^{15}$ The indeterminacy arises in our model mainly because of the inelastic demand. This problem can be removed if a chock price is introduced above which the demand is zero or alternatively if we allow for a negatively sloped demand function (which is not considered here for the sake of tractability). Following Dixon (1984) and Maskin (1986), in either case a mixed strategy equilibrium exists. Interestingly, the equilibrium involves a set of prices higher than $\delta c_{2}$ in the first period. No firm has an incentive to set a price lower than $\delta c_{2}$ since it could sell in the second period and obtain the same profits. However, it follows from the previous discussion that a firm recognizes that it can increase the price in the first period because the rival's inability to commit to order $d$ implies that a part of the market will remain uncovered. This yields an upper bound of the price range at the monopoly price on the residual demand. Therefore, the price response to the input cost shock can be even more severe than with higher future discounting.
} 
first period is profitable or not. Indeed, it turns out to be unprofitable since the non-deviating firm does not order any positive quantity (which cannot be sold in the first period) and therefore the undercutting firm does not benefit from a reduction in the input costs. In equilibrium, the price is equal to $c_{1}$ in the first period and to $c_{2}$ in the second period. Since we allow for voluntary trading, a part of the demand may remain uncovered.

Notably, we can exclude the existence of other equilibria. In particular, prices above $c_{1}$ in the first period cannot be supported as an equilibrium because of the usual Bertrand argument. Any equilibrium cannot sustain prices below $c_{1}$ since a firm has an incentive to deviate upward in the first period and set a price above $c_{1}$. An interesting feature of the quantity setting game following this deviation is that it does not exhibit any equilibrium in pure strategies. The firm with the price below $c_{1}$ strictly prefers to order either zero or $d$ to any other strategy. However, this firm cannot order zero with probability 1 in equilibrium, since the rival would purchase $d$, which induces the firm to deviate by ordering a positive quantity as the input cost $\widetilde{c}_{1}$ declines. Moreover, the firm cannot order $d$ with probability 1 in equilibrium, otherwise the rival would purchase zero and the associated cost $\widetilde{c}_{1}=c_{1}$ would entail losses. The quantity setting game resembles a game of matching pennies, and it turns out that the firm with the price above $c_{1}$ sells some quantity at a positive margin while the firm with the price below $c_{1}$ mixes between ordering zero and $d$ so that it earns zero (expected) profits and the market is fully covered.

\section{Robustness}

\subsection{Mode of competition}

In our model the firms set prices and then decide on quantities, which is known in the literature as production to order. The case in which prices and quantities are determined simultaneously also deserves some attention. The main technical problem identified in a simple static framework by Chowdhury (2005) is the nonexistence of pure strategy equilibria. Under some mild conditions (such as a finite price at which profits are maximized), Allen and Hellwig (1986) and Dasgupta and Maskin (1986) establish the general existence of an equilibrium in mixed strategies. Since in our framework the strategic role of profitable storage does not crucially depend on the observability of the rivals' prices, we expect that our results will carry over in this scenario, although the derivation of equilibria would be more cumbersome. The case of a negative shock does not add any element of interest to the analysis, since storing is unprofitable and the equilibrium of the static game persists.

It is also worth exploring whether the strategic role of storing as an explanation for asymmetric pricing emerges even in a monopolistic setting or under alternative competitive structures such as Cournot competition. Indeed, we can show that storing affects the pricing strategy of a monopolist in several possible manners. Similar results hold when firms compete in Cournot fashion. ${ }^{16}$ To make the problem interesting, consider a standard downward sloping demand function. When the shock is negative, storing is unprofitable and the monopoly price equalizes current marginal

\footnotetext{
${ }^{16}$ All our claims can be proved formally. Computations are available upon request.
} 
revenues and the current (constant) marginal costs in each period. When the shock is positive and storing is profitable, $\delta \geq \frac{c_{1}}{c_{2}}$, the monopolist's pricing strategy depends on the size of the storage capacity. If the capacity is so large that the firm can cover the demand in two periods, the price in the first period still equalizes current marginal revenues and current marginal costs, while the price in the second period equalizes the discounted marginal revenues and the first period marginal costs. This implies that in the first period the price adjustment follows the same pattern as with a negative shock, but the second period price adjustment is smaller. When the storage capacity is tight, the monopolist faces a trade-off between selling the quantity in the first period or storing it for the second period. In this case the firm prefers to increase the price in the first period in order

to reduce its current sales and store more output for the next period. Specifically, if the size of the storage capacity is very small (below a certain threshold level), the monopolist will also produce (or purchase from its distributor) in the second period and the level of prices in the two periods cannot be unambiguously ranked. Interestingly, the price may even decrease in the second period despite the increase in the input costs. If the capacity is relatively less stringent (above the threshold level), the monopolist will only produce (or purchase from its distributor) in the first period and it will prefer to sell more in the first period than in the second period (due to the discount factor). In line with the empirical evidence, the price adjustment in the first period turns out to be more pronounced than with a negative shock, while the opposite occurs in the second period.

\subsection{Storage capacity}

Throughout the analysis we assume that a firm's storage capacity is exogenous and equal to the market demand in each period. As argued in section 3, a capacity level equal to the demand in each period is a reasonable assumption, since each firm is able to undercut the rival and serve the whole market. Less interesting is the case in which the capacity is below $d$. In such a scenario, each firm is a monopolist on the residual demand, which creates the incentive to raise prices above marginal costs even in the absence of a shock. Following Levitan and Shubik (1972) and Osborne and Pitchik (1986), it can be shown that there exist mixed strategy equilibria involving prices above marginal costs. A positive shock that entails higher future costs still creates opportunities for profitable storing and, in line with our results, prices will increase. In such a case, however, the analysis would be less transparent.

If the firm's capacity is larger than $d$, the analysis becomes more cumbersome. In a two-period game, the firms may not be able to sell their initial orders. Our conclusions remain valid but the incentive to immediately increase prices with a positive shock is mitigated. Notably, an increase in the number of periods fully restores our results.

Related to this discussion is the question of the robustness of our results to an increase in the number of periods. If the game is long enough so that firms are able to sell all quantities at a certain future point in time, no price war occurs between firms to empty their depositories and the price randomization in Lemma $1 \mathrm{~B}$ no longer emerges. In this case, if a positive shock occurs the price adjustment takes place gradually, provided that the discounted profits are equal across 
periods.

\subsection{Input costs}

In our setting input costs move in a deterministic way. As argued in section 4.2, nothing would change substantially if we assume that costs follow a stochastic process, provided that future costs are expected to depart from the current ones. One may wonder why in our model no trader can exploit arbitrage opportunities arising from expected cost increases in the future. For instance, in the gasoline market intermediaries could store some quantities and increase the current prices charged to retailers. Notably, even in this case the mechanism described in our analysis goes through but it applies to a different level of the supply chain.

\subsection{Demand function}

Consumer demand is supposed to be fully inelastic. This assumption is made for the sake of tractability and turns out to be innocuous for our purposes. It can certainly be the case that the demand function is not perfectly rigid but is negatively sloped. This makes upward price deviations less attractive since the demand is reduced, while downward deviations become more appealing. With a negatively sloped demand function $d($.$) , we have d\left(c_{1}\right)>d\left(\delta c_{2}\right)$ for $\delta>\frac{c_{1}}{c_{2}}$. If the storage capacity of each retailer is $d\left(c_{1}\right)$, it follows that when both firms purchase $d\left(c_{1}\right)$ in the first period in order to sell it profitably in the two periods some quantity will remain unsold. Clearly, this cannot be an equilibrium and the firms will have an incentive to undercut below $\delta c_{2}$. It is well known in the literature that in this setting a mixed strategy equilibrium exists. The incentive to increase prices immediately with a positive shock should persist, even though it is softer.

\section{Concluding remarks}

In this paper we provide a theoretical explanation for the well-established phenomenon of asymmetric price adjustments to input cost shocks. Using a model of dynamic price competition, we show that the presence of profitable storing allows competitive firms to credibly commit to immediately increase their prices above current marginal costs when they anticipate higher input costs. As a result, competition is mitigated and firms earn positive profits. If input costs are expected to decline, the price adjustment is slower and prices reflect current marginal costs, which entails zero profits. Our study suggests that empirical models should also consider the impact of anticipated cost changes when estimating price patterns over time. This can be done via an investigation of the firms' price decisions before a cost change materializes.

Even though our results are shown in a Bertrand-Edgeworth framework, profitable storing remains the driving force for asymmetric pricing in alternative standard market structures such as monopoly or Cournot competition. Our findings apply to the gasoline market as well as to other important sectors characterized by storage opportunities. For instance, banks that issue deposits and employ the funds to provide loans generally adjust the amount of liquidity they possess and 
the rates on their loans in response to the announcement of a change in the central bank's interest rate.

Our analysis is potentially significant in different aspects. We develop a model that focuses on the supply side and derives the pattern of asymmetric pricing as a unique prediction of the game, abstracting from market imperfections such as collusion among firms or limited information of consumers. Our results recommend an empirical investigation that disentangles the well-known demand side effects from the supply side effects identified in our analysis.

Acknowledgments We thank Helmut Bester, Volker Nocke, Nicolas Schutz, Konrad Stahl and Roland Strausz for valuable comments and suggestions. We also thank the participants at the SFB-TR15 Workshop for Young Researchers 2014 in Mannheim, the SFB-TR15 Conference 2014 in Caputh and the ASSET Conference 2014 in Aix-en-Provence.

\section{Appendix}

This Appendix collects the proofs.

Proof of Lemma 1. In the quantity setting game, the analysis proceeds through the following cases:

(i) $p_{2 i}=p_{2 j}>c_{2} \Rightarrow q_{2 i}^{m}=\frac{d}{2}, i=1,2$.

(ii) $p_{2 i}=p_{2 j}=c_{2} \Rightarrow \sum_{i=1}^{2} q_{2 i}^{m} \leq d$.

(iii) $p_{2 i}>p_{2 j}>c_{2} \Rightarrow q_{2 i}^{m}=0 ; q_{2 j}^{m}=d$.

(iv) $p_{2 i}>p_{2 j}=c_{2} \Rightarrow q_{2 i}^{m}=d-q_{2 j}^{m}$; $q_{2 j}^{m} \in\left[q_{1 j}^{r}, d\right]$.

(v) $p_{2 i}>c_{2}>p_{2 j} \Rightarrow q_{2 i}^{m}=d-q_{2 j}^{m} ; q_{2 j}^{m}=q_{1 j}^{r}$.

(vi) $p_{2 i}=c_{2}>p_{2 j} \Rightarrow q_{2 i}^{m} \in\left[\min \left\{q_{1 i}^{r}, d-q_{2 j}^{m}\right\}, d-q_{2 j}^{m}\right] ; q_{2 j}^{m}=q_{1 j}^{r}$.

(vii) $p_{2 i}=p_{2 j}<c_{2} \Rightarrow q_{2 i}^{m}=\min \left\{q_{1 i}^{r}, \max \left\{\frac{d}{2}, d-q_{2 j}^{m}\right\}\right\}, i=1,2$.

(viii) $p_{2 j}<p_{2 i}<c_{2} \Rightarrow q_{2 i}^{m}=\min \left\{q_{1 i}^{r}, d-q_{2 j}^{m}\right\} ; q_{2 j}^{m}=q_{1 j}^{r}$.

A. Suppose $\sum_{i=1}^{2} q_{1 i}^{r} \leq d$. The candidate equilibria in the price setting game are (a) $p_{2 i}=p_{2 j}=c_{2}$; (b) $p_{2 i}=p_{2 j}>c_{2}$; (c) $p_{2 i}>p_{2 j} \geq c_{2}$; (d) $p_{2 i} \geq c_{2}>p_{2 j}$; (e) $p_{2 i}<c_{2}, i=1,2$.

We first show that candidate (a) is an equilibrium. It follows from (ii) that the equilibrium in the quantity setting game is $q_{2 i}^{m} \in\left[q_{1 i}^{r}, d\right]$, which yields profits for firm $i$ equal to $\pi_{2 i}=c_{2} q_{1 i}^{r} .{ }^{17}$ Given (iv), when $q_{2 j}^{m}=d$ we can see that no profitable upward price deviation exists. From (vi) it follows that there is no incentive to deviate downward either. Therefore, the candidate (a) is an equilibrium, which implies $p_{2 i}^{*}=c_{2}, \sum_{i=1}^{2} q_{1 i}^{m *} \leq d$ and $q_{2 i}^{r *}=0, i=1,2$.

We now show that the price equilibrium (a) is unique. Candidate (b) is not an equilibrium since if firm $i$ sets a price $p_{2 j}-\epsilon>c_{2}$, where $\epsilon>0$ and infinitely small, it can get higher profits.

\footnotetext{
${ }^{17}$ Indeed, there are other equilibria in the quantity setting game when firm $i$ carries less than $\frac{d}{2}$ from the first period and firm $j$ carries more than $\frac{d}{2}$. In these equilibria, firm $i$ buys some quantity at $c_{2}$ and serves up to half the market, while firm $j$ cannot sell all its reserves. However, this cannot support a SPNE in the second period continuation game, since firm $i$ has an incentive to undercut in order to sell all its reserves.
} 
Candidate (c) is not an equilibrium since firm $j$ can set $p_{2 j}^{\prime} \in\left(p_{2 j}, p_{2 i}\right)$ and get higher profits. Candidate $(\mathrm{d})$ is not an equilibrium since firm $j$ can set a price $p_{2 j}^{\prime} \in\left(p_{2 j}, c_{2}\right)$ and gain by selling its reserves. If it does not have any reserve, firm $i$ can gain by setting a higher price. Candidate (e) is not an equilibrium since both firms have an incentive to raise their prices. Therefore, the outcome $\left(p_{2 i}^{*}, q_{2 i}^{m *}, q_{2 i}^{r *}\right)$ is an equilibrium in the second period continuation game if and only if $p_{2 i}^{*}=c_{2}$, $\sum_{i=1}^{2} q_{1 i}^{m *} \leq d$ and $q_{2 i}^{r *}=0, i=1,2$.

B. Suppose $\sum_{i=1}^{2} q_{1 i}^{r}>d$. Since the second period is the final period of the game, each firm wants to exhaust its reserves. In equilibrium the market clears (the two firms in aggregate fully cover the market) and a firm's reserve is the residual from the first period that the firm is unable to sell in the second period, namely, $\sum_{i=1}^{2} q_{2 i}^{m *}=d$ and $q_{2 i}^{r *}=\max \left\{0, q_{1 i}^{r *}-q_{2 i}^{m *}\right\}, i=1,2$. Since the firms do not order any additional quantities, this game corresponds to a price competition game with (a)symmetric capacity constraints. We know from Levitan and Shubik (1972) and Osborne and Pitchik (1986) that there exists an equilibrium (which is generally unique), where firms randomize in prices within the support $\left[\underline{p}_{2}^{*}, \bar{p}_{2}^{*}\right] \subseteq\left[0, c_{2}\right]$. Any price above $c_{2}$ cannot be chosen with positive probability, since price undercutting is always profitable. Moreover, choosing with probability 1 a price equal to $c_{2}$ cannot be sustained as an equilibrium since each firm has an incentive to undercut the rival and sell off all its reserves.

Proof of Remark 1. We know from Lemma 1 that $p_{2 i}^{*} \leq c$. For $\delta<1$ no firm has an incentive to store some quantity for the next period, i.e., $q_{\tau i}^{r *}=0, \tau, i=1,2$. Therefore, as in Chowdhury (2005), we have $p_{\tau i}^{*}=c$ and $\sum_{i=1}^{2} q_{\tau i}^{m *} \leq d, \tau, i=1,2$, in equilibrium. For $\delta=1$, storing is not harmful if $\sum_{i=1}^{2} q_{1 i}^{r} \leq d$. Therefore, any outcome $\sum_{i=1}^{2} q_{1 i}^{r} \leq d$ such that $p_{\tau i}^{*}=c$ and $\sum_{i=1}^{2} q_{\tau i}^{m *} \leq d$, $\tau, i=1,2$, can be sustained in equilibrium.

Proof of Proposition 1. A. For $\delta \geq \frac{c_{1}}{c_{2}}$ each firm finds it profitable to order one unit today at $c_{1}$ and sell it tomorrow if the price in the second period is $c_{2}$. First, we argue that no equilibrium exists which involves a price $c_{1}<p_{1 i}<\delta c_{2}, i=1,2$. Assume that there exists an equilibrium in the quantity setting game which supports these prices as an equilibrium strategy. Such an equilibrium must imply that each firm will order $d$ in the first period, i.e., $q_{1 i}=d, i=1,2$, since for any given quantity of the rival a firm can sell profitably in either period. Note that the outcome $q_{1 i}^{m}=0$, $q_{2 i}^{m}=d$ with $q_{1 j}^{m}=d, q_{2 j}^{m}=0$ (and the reverse) cannot be supported as an equilibrium in quantities for $c_{1} \leq p_{1 i}<\delta c_{2}, i=1,2$. The rationale is the following. Suppose that firm $j$ deviates in the first period and stores a quantity $\widetilde{q}_{1 j}>0$ for the next period. It follows from the proof of Lemma $1 \mathrm{~B}$ that a (unique) mixed strategy equilibrium in the second period continuation game exists. Firm $j$ can always choose a sufficiently small quantity $\widetilde{q}_{1 j}>0$ such that the lower bound of the price interval is higher than $p_{1 j} / \delta$. This implies that firm $j$ which stores $\widetilde{q}_{1 j}$ for the next period gains from such a deviation. This result is crucial in order to show that there exists an incentive for upward deviation in prices in the first period. Let $L_{i} \equiv\left\{\pi_{i}: \pi_{i}=\left(p_{1 i}-c_{1}\right) q_{1 i}^{m}+\left(\delta p_{2 i}-c_{1}\right) q_{2 i}^{m}\right\}$ be the set of firm $i$ 's profits associated with the candidate $c_{1} \leq p_{1 i}<\delta c_{2}, i=1,2$, if an equilibrium in quantities exists. From the previous discussion and the result in Lemma 1B it follows that $\sup \left(L_{i}\right)<\left(\delta c_{2}-c_{1}\right) d$. Now, we characterize the equilibrium in the quantity setting game in the first period following a 
deviation such that $p_{1 i}^{\prime}>\delta c_{2}>p_{1 j}$. Let $S_{i} \equiv\left\{\pi_{i}^{\prime}: \pi_{i}^{\prime}=\left(p_{1 i}^{\prime}-c_{1}\right) q_{1 i}^{m^{\prime}}+\left(\delta p_{2 i}^{\prime}-c_{1}\right) q_{2 i}^{m^{\prime}}\right\}$ be the set of firm $i$ 's profits associated with $p_{1 i}^{\prime}>\delta c_{2}>p_{1 j}$. Since firm $i$ has a strict preference for selling today while firm $j$ has a strict preference for selling tomorrow, firm $i$ never wants to engage in a price war in the second period, which implies that $d$ will be sold in both periods and $p_{2 i}^{\prime}=c_{2}$. Moreover, following the previous argument, firm $j$ will always prefer to bring a positive quantity to the second period, which implies that firm $i$ can sell something in the first period. Therefore, $\inf \left(S_{i}\right)>\left(\delta c_{2}-c_{1}\right) d>\sup \left(L_{i}\right)$. Since an equilibrium in quantities with $p_{1 i}^{\prime}>\delta c_{2}>p_{1 j}$ exists (e.g., $q_{1 i}^{m}=d, q_{2 i}^{m}=0$ and $q_{1 j}^{m}=0, q_{2 j}^{m}=d$ ), it follows that firm $i$ has an incentive to deviate and $c_{1} \leq p_{1 i}<\delta c_{2}, i=1,2$, cannot be an equilibrium.

It can immediately be shown that $p_{1 i}>\delta c_{2}>p_{1 j}$ cannot be an equilibrium, since firm $j$ can always set a price $p_{1 j}^{\prime}=p_{1 i}-\epsilon>\delta c_{2}$, where $\epsilon>0$ and infinitely small, and gain. Moreover, $p_{1 i}=\delta c_{2}>p_{1 j}$ cannot be an equilibrium, either. Firm $j$ does not have any incentive to deviate only when $q_{1 j}^{m}=0$ and $q_{2 j}^{m}=d$ in equilibrium. However, in this case firm $i$ gets profits $\left(\delta c_{2}-c_{1}\right) d$ and we know from the previous discussion that it can set $p_{1 i}^{\prime}>\delta c_{2}>p_{1 j}$ and gain. It is also straightforward to argue that an equilibrium which involves $p_{1 i} \geq \delta c_{2}, i=1,2$, where at least one firm sets $p_{1 i}>\delta c_{2}$ cannot be sustained as the standard undercutting reasoning applies.

The only price candidate that we have not investigated yet is $p_{1 i}=\delta c_{2}, i=1,2$. Note that, irrespective of the direction of price deviation by firm $i$, there exists an equilibrium in the quantity setting game where $q_{1 i}^{m}=0, q_{2 i}^{m}=d$ and $q_{1 j}^{m}=d, q_{2 j}^{m}=0$. In this case, no deviation is profitable. A similar argument applies for any price deviation by firm $j$. Then, an outcome is a SPNE if and only if $p_{1 i}^{*}=\delta p_{2 i}^{*}=\delta c_{2}, \sum_{i=1}^{2} q_{\tau i}^{m *}=d, q_{1 i}^{r *}=d-q_{1 i}^{m *}$ and $q_{2 i}^{r *}=0, \tau, i=1,2$.

B. For $\delta<\frac{c_{1}}{c_{2}}$, storing is never profitable, i.e., $q_{\tau i}^{r *}=0, \tau, i=1,2$. Therefore, the standard Bertrand rationale applies and an outcome is a SPNE if and only if $p_{\tau i}^{*}=c_{\tau}, \sum_{i=1}^{2} q_{\tau i}^{m *} \leq d$ and $q_{\tau i}^{r *}=0, \tau, i=1,2$.

Proof of Proposition 2. Since storing is not profitable, the same argument as in the proof of Proposition 1B applies.

Proof of Proposition 3. Let $\delta \geq \frac{c_{1}}{c_{2}}$. We first derive the equilibrium in the first period quantity setting game when prices are $p_{1 i}=\delta p_{2 i}=\delta c_{2}, i=1,2$. Note that in equilibrium both firms will order $\sum_{i=1}^{2} q_{1 i} \geq d$, since the marginal (and average) cost in (4) is $\widetilde{c}_{1}=c_{1}$ for $\sum_{i=1}^{2} q_{1 i} \leq d$. The quantity ordered by firm $i$ in the first period can be written as $q_{1 i}=\widetilde{q}_{1 i}^{e}+q_{1 i}^{e}$, where $\widetilde{q}_{1 i}^{e}$ denotes the quantity ordered by firm $i$ such that together with the corresponding quantity ordered by firm $j$ it holds $\sum_{i=1}^{2} \widetilde{q}_{1 i}^{e}=d$. For a given $\widetilde{q}_{1 i}^{e}, i=1,2$, firm $i$ chooses $q_{1 i}^{e}$ and faces an average cost equal to $\widetilde{c}_{1}=\frac{c_{1} d+c_{2} \sum_{i=1}^{2} q_{1 i}^{e}}{d+\sum_{i=1}^{2} q_{1 i}^{e}}$. Firm $i$ 's maximization problem is

$$
\max _{q_{1 i}^{e} \geq 0} \delta c_{2}\left(\widetilde{q}_{1 i}^{e}+q_{1 i}^{e}\right)-\widetilde{c}_{1}\left(\widetilde{q}_{1 i}^{e}+q_{1 i}^{e}\right)
$$

which yields the following first-order condition for an interior solution 


$$
\frac{\delta c_{2}\left(d+\sum_{i=1}^{2} q_{1 i}^{e}\right)^{2}-c_{1} d\left(d+q_{1 j}^{e}-\widetilde{q}_{1 i}^{e}\right)-c_{2}\left[\left(\sum_{i=1}^{2} q_{1 i}^{e}\right)^{2}+d\left(2 q_{1 i}^{e}+q_{1 j}^{e}+\widetilde{q}_{1 i}^{e}\right)\right]}{\left(d+\sum_{i=1}^{2} q_{1 i}^{e}\right)^{2}}=0 .
$$

Combining terms implies

$$
q_{1 i}^{e}\left(q_{1 j}^{e}\right)=-\left(d+q_{1 j}^{e}\right)+\frac{\left(c_{2}-c_{1}\right)^{\frac{1}{2}}\left[c_{2} d\left(d+q_{1 j}^{e}-\widetilde{q}_{1 i}^{e}\right)(1-\delta)\right]^{\frac{1}{2}}}{c_{2}(1-\delta)} .
$$

Equation (A.1) gives the best response function for firm $i$. In the same vein, we obtain the best response function for firm $j$

$$
q_{1 j}^{e}\left(q_{1 i}^{e}\right)=-\left(d+q_{1 i}^{e}\right)+\frac{\left(c_{2}-c_{1}\right)^{\frac{1}{2}}\left[c_{2} d\left(d+q_{1 i}^{e}-\widetilde{q}_{1 j}^{e}\right)(1-\delta)\right]^{\frac{1}{2}}}{c_{2}(1-\delta)} .
$$

Solving (A.1) and (A.2) simultaneously implies that in the unique symmetric equilibrium the quantity ordered by firm $i$ in the first period is

$$
q_{1 i}^{*}=\widetilde{q}_{1 i}^{e *}+q_{1 i}^{e *}=\frac{\left(c_{2}-c_{1}\right) d}{4 c_{2}(1-\delta)}, i=1,2 .
$$

Since $\sum_{i=1}^{2} \widetilde{q}_{1 i}^{e}=d$, (A.3) is a solution for firm $i$ 's maximization problem if $\frac{\left(c_{2}-c_{1}\right) d}{4 c_{2}(1-\delta)}-\frac{d}{2} \geq 0$, which implies $\delta \geq \frac{1}{2}\left(1+\frac{c_{1}}{c_{2}}\right)$. Firm $i$ 's profits are given by $\pi_{i}^{*}=\left(\delta c_{2}-\frac{c_{1} d+c_{2} \sum_{i=1}^{2} q_{1 i}^{e *}}{d+\sum_{i=1}^{2} q_{1 i}^{e *}}\right) q_{1 i}^{*}=\frac{\left(c_{2}-c_{1}\right) d}{4}>0$. In the sequel, we split the analysis according the value of the discount factor $\delta$.

A. Assume $\delta \geq \frac{1}{4}\left(3+\frac{c_{1}}{c_{2}}\right)$. For $\delta=\frac{1}{4}\left(3+\frac{c_{1}}{c_{2}}\right)$ we obtain from (A.3) $q_{1 i}^{*}=d, i=1,2$. Since $\frac{\partial q_{1 i}^{*}}{\partial \delta}>0$, it follows that $q_{1 i}^{*}=d, i=1,2$, still holds for higher values of $\delta$. In words, in the first period each firm orders its full capacity. Therefore, the analysis of Proposition 1 carries over and $p_{1 i}^{*}=\delta p_{2 i}^{*}=\delta c_{2}$ are the equilibrium prices.

B. Assume $\frac{c_{1}}{c_{2}} \leq \delta<\frac{1}{4}\left(3+\frac{c_{1}}{c_{2}}\right)$. We first demonstrate that the candidate $p_{1 i}=\delta p_{2 i}=\delta c_{2}$, $i=1,2$, cannot be an equilibrium since a firm has an incentive to (infinitely) increase its price in the first period. Such a deviation would not be profitable if and only if the rival orders and sells $d$ in the first period. We show that this cannot be an equilibrium in the quantity setting game (if it exists at all). Note that, since firm $i$ 's (marginal) revenue following the deviation is higher (or at least not lower), firm $i$ does not want to buy less than in the candidate equilibrium and, in response, the non-deviating firm $j$ does not want to buy more. For $\delta \geq \frac{1}{2}\left(1+\frac{c_{1}}{c_{2}}\right)$, the equilibrium in the quantity setting game with $p_{1 i}^{*}=\delta p_{2 i}^{*}=\delta c_{2}$ is still described by (A.3). Therefore, following an upward price deviation of firm $i$, the non-deviating firm $j$ will not buy more than $\frac{\left(c_{2}-c_{1}\right) d}{4 c_{2}(1-\delta)}<d$. For $\delta<\frac{1}{2}\left(1+\frac{c_{1}}{c_{2}}\right)$, the solution in (A.3) is no longer valid. This implies that firm $i$ 's maximization problem yields $q_{1 i}^{e}=0$. In words, for prices $p_{1 i}=\delta p_{2 i}=\delta c_{2}, i=1,2$, the firms do not want to order in aggregate more than $d$. For our purposes, it is sufficient to show that an equilibrium in 
the quantity setting game with $p_{1 i}=\delta p_{2 i}=\delta c_{2}, i=1,2$, cannot involve $q_{1 i}=0$ and $q_{1 j}=d$. This is because, given that firm $j$ buys $d$ in the first period, firm $i$ 's marginal revenue is higher than the marginal cost at zero, i.e., $\delta c_{2} \geq c_{1}$, and therefore firm $i$ has an incentive to order some quantity in the first period (and sell it in either period). This implies that the non-deviating firm $j$ will buy less than $d$. As a consequence, for $\frac{c_{1}}{c_{2}} \leq \delta<\frac{1}{4}\left(3+\frac{c_{1}}{c_{2}}\right)$, firm $i$ can set an infinitely high price to cover the residual demand in the first period and be better off.

As long as the first period prices are higher than $\delta c_{2}$, each firm has an incentive to undercut to sell in the first period. Moreover, any price below $\delta c_{2}$ cannot be supported as an equilibrium, since the non-deviating firm will always prefer to sell at least some positive quantity in the next period while the rival could increase the price and sell profitably in the first period. Along the same lines, it can be shown that an asymmetric price configuration (one firm sets the price above $\delta c_{2}$ and the rival below $\left.\delta c_{2}\right)$ also cannot be an equilibrium. Hence, for $\frac{c_{1}}{c_{2}} \leq \delta<\frac{1}{4}\left(3+\frac{c_{1}}{c_{2}}\right)$, there is no equilibrium in the price setting game and no SPNE exists in pure strategies. Since the rigid demand allows a deviating firm to set an infinite price, no SPNE exists even in mixed strategies.

C. Assume $\delta<\frac{c_{1}}{c_{2}}$. The proof of Proposition 1B is replicated.

Proof of Proposition 4. First note that $q_{1 i}^{r}>0$ is never optimal since $\widetilde{c}_{1}>c_{2} \geq p_{2 i}$ (from Lemma $1)$. It is straightforward to show that any price configuration where $p_{1 i}>p_{1 j} \geq c_{1}, p_{1 i}>c_{1}>p_{1 j}$ or $p_{1 i}=p_{1 j}>c_{1}$ cannot be sustained as an equilibrium since the standard undercutting rationale applies.

To proceed, it is useful to determine the outcome in the first period quantity setting game for some relevant cases:

(i) $p_{1 i}>p_{1 j}=c_{1} \Rightarrow q_{1 i}^{m}=0 ; q_{1 j}^{m}=d$. Any $q_{1 i}^{m}>0$ cannot be an equilibrium, since firm $j$ 's best response would be $q_{1 j}^{m}=d$ (which guarantees positive profits since $c_{1}>\widetilde{c}_{1}$ ), and firm $i$ would make losses.

(ii) $p_{1 i}>c_{1}>p_{1 j} \geq \frac{c_{1}+c_{2}}{2}$. There does not exist any pure strategy Nash equilibrium. The reason is that there is a critical threshold $\widetilde{q}_{1 i} \in(0, d]$ at which $\pi_{j}=\left(p_{1 j}-\widetilde{c}_{1}\right) d=0$ and $\pi_{j}>0$ if and only if $q_{1 i}>\widetilde{q}_{1 i}$. Hence, the best response function of firm $j$ is discontinuous and jumps from $q_{1 j}\left(q_{1 i}\right)=0$ for $q_{1 i}<\widetilde{q}_{1 i}$ to $q_{1 j}\left(q_{1 i}\right)=d$ for $q_{1 i} \geq \widetilde{q}_{1 i}$. For our aims, it is sufficient to show that in any mixed strategy Nash equilibrium we must have that (a) the (expected) profit of firm $i$ is strictly positive for $p_{1 i}>c_{1}$, and (b) the (expected) profit of firm $j$ is zero. Afterwards, we demonstrate that such an equilibrium exists. The result (a) follows since there exists a quantity $q_{1 i}<\widetilde{q}_{1 i}$ such that $\pi_{i}=\left(p_{1 i}-\widetilde{c}_{1}\right) q_{1 i}>0$ for $p_{1 i}>c_{1} \geq \widetilde{c}_{1}$ and $\pi_{j}=\left(p_{1 j}-\widetilde{c}_{1}\right) d<0$. To see the result (b), recall that any strategy $q_{1 j} \in(0, d)$ is strictly dominated by the two extreme values 0 and $d$. The only strategy profile which is part of a mixed strategy Nash equilibrium is the set $\{0, d\}$. Since any pure strategy which is part of a mixed strategy Nash equilibrium must yield the same (expected) payoff and $q_{1 j}=0$ gives zero payoff, then $q_{1 j}=d$ must also give zero, which implies that the profit of firm $j$ is zero. A mixed strategy Nash equilibrium in this subgame prescribes that firm $i$ chooses with probability 1 the quantity $\widetilde{q}_{1 i}$ and firm $j$ randomizes between zero and $d$ such that its expected quantity equals $d-\widetilde{q}_{1 i}$. 
(iii) $p_{1 i}=c_{1}>p_{1 j} \geq \frac{c_{1}+c_{2}}{2}$. The equilibrium described in (ii) still holds true, yet in addition we have an equilibrium in pure strategies where $q_{1 i}=0, i=1,2$.

(iv) $p_{1 i}<c_{1} \Rightarrow q_{1 i}^{m}=0, i=1,2$. Each firm has a dominant strategy not to serve the market.

Combining (ii) and (iv) it is easy to argue that any $c_{1}>p_{1 i} \geq p_{1 j}$ or $p_{1 i}=c_{1}>p_{1 j}$ cannot be an equilibrium since firm $i$ has an incentive to increase the price above $c_{1}$ and gain.

It remains to be shown that $p_{1 i}=c_{1}, i=1,2$, is chosen in equilibrium. From (iii) it follows that firm $i$ does not have an incentive to deviate downwards. Similarly, if firm $i$ deviates upwards, we are in the quantity equilibrium described in (i) so that firm $i$ does not gain from deviation.

Hence, any outcome $\left(p_{\tau i}^{*}, q_{\tau i}^{m *}, q_{\tau i}^{r *}\right)$, where $p_{\tau i}^{*}=c_{\tau}, \sum_{i=1}^{2} q_{\tau i}^{m *} \leq d$ and $q_{\tau i}^{r *}=0, \tau, i=1,2$, sustains a SPNE.

\section{References}

Allen, B., Hellwig, M. (1986). Bertrand-Edgeworth oligopoly in large markets. Review of Economic Studies, 53(2), 175-204.

Amihud, Y., Mendelson, H. (1983). Price smoothing and inventory. Review of Economic Studies, $50(1), 87-98$.

Asplund, M., Eriksson, R., Friberg, R. (2000). Price adjustments by a gasoline retail chain. Scandinavian Journal of Economics, 102(1), 101-121.

Bacon, R. W. (1991). Rockets and feathers: The asymmetric speed of adjustment of UK retail gasoline prices to cost changes. Energy Economics, 13(3), 211-218.

Blair, B. F., Rezek, J. P. (2008). The effects of hurricane Katrina on price pass-through for Gulf coast gasoline. Economics Letters, 98(3), 229-234.

Borenstein, S., Cameron, A. C., Gilbert, R. (1997). Do gasoline prices respond asymmetrically to crude oil price changes?. Quarterly Journal of Economics, 112(1), 305-339.

Borenstein, S., Shepard, A. (1996). Dynamic pricing in retail gasoline markets. Rand Journal of Economics, 27(3), 429-451.

Borenstein, S., Shepard, A. (2002). Sticky prices, inventories, and market power in wholesale gasoline markets. Rand Journal of Economics, 33(1), 116-139.

Cabral, L., Fishman, A. (2012). Business as usual: A consumer search theory of sticky prices and asymmetric price adjustment. International Journal of Industrial Organization, 30(4), 371-376.

Chen, H. A., Levy, D., Ray, S., Bergen, M. (2008). Asymmetric price adjustment in the small. Journal of Monetary Economics, 55(4), 728-737.

Chesnes, M. (2012). Asymmetric pass-through in U.S. gasoline prices. U.S. Federal Trade Commission Bureau of Economics Working Paper No. 302. 
Chowdhury, P. R. (2005). Bertrand-Edgeworth duopoly with linear costs: A tale of two paradoxes. Economics Letters, 88(1), 61-65.

Chowdhury, P. R. (2009). Bertrand competition with non-rigid capacity constraints. Economics Letters, 103(1), 55-58.

Dasgupta, P., Maskin, E. (1986). The existence of equilibrium in discontinuous economic games, II: Applications. Review of Economic Studies, 53(1), 27-41.

Davidson, C., Deneckere, R. (1986). Long-run competition in capacity, short-run competition in price, and the Cournot model. Rand Journal of Economics, 17(3), 404-415.

Deltas, G. (2008). Retail gasoline price dynamics and local market power. Journal of Industrial Economics, 56(3), 613-628.

Dixon, H. (1984). The existence of mixed strategy equilibria in a price-setting oligopoly with convex costs. Economics Letters, 16(3-4), 205-212.

FTC (2006). The Federal Trade Commission investigation of gasoline price manipulation and post-Katrina gasoline price increases: A commission report to congress. Document available at http://www.ftc.gov/reports/federal-trade-commission-investigation-gasolineprice-manipulation-post-katrina-gasoline.

Green, R. C., Li, D., Schürhoff, N. (2010). Price discovery in illiquid markets: Do financial asset prices rise faster than they fall?. Journal of Finance, 65(5), 1669-1702.

Hannan, T. H., Berger, A. N. (1991). The rigidity of prices: Evidence from banking industry. American Economic Review, 81(4), 938-945.

Kreps, D. M., Scheinkman, J. A. (1983). Quantity precommitment and Bertrand competition yield Cournot outcomes. Bell Journal of Economics, 14(2), 326-337.

Leffler, K. (2007). Gas price study. Phase I: Fact-finding. Document available at http://agportals3bucket.s3.amazonaws.com/uploadedfiles/Another/Safeguarding_Consumers/Antitrust/Unfair_ Trade_Practices/Gas_Prices/2007 Gas Price Study - phase I.pdf.

Levitan, R., Shubik, M. (1972). Price duopoly and capacity constraints. International Economic Review, 13(1), 111-122.

Lewis, M. S. (2011). Asymmetric price adjustment and consumer search: An examination of the retail gasoline market. Journal of Economics and Management Strategy, 20(2), 409-449.

Maskin, E. (1986). The existence of equilibrium with price-setting firms. American Economic Review, 76(2), Papers and Proceedings of the Ninety-Eighth Annual Meeting of the American Economic Association, 382-386. 
NACS (2013). Retail fuels report. Document available at http://www.nacsonline.com/Your Business/FuelsReports/GasPrices_2013/Documents/CFR2013_FullReport.pdf.

Osborne, M. J., Pitchik, C. (1986). Price competition in a capacity constraint duopoly. Journal of Economic Theory, 38(2), 238-260.

Peltzman, S. (2000). Prices rise faster than they fall. Journal of Political Economy, 108(3), 466-502.

Reagan, P. B. (1982). Inventory and price behaviour. Review of Economic Studies, 49(1), 137-142.

Reagan, P. B., Weitzman, M. L. (1982). Asymmetries in price and quantities adjustments by the competitive firm. Journal of Economic Theory, 27(2), 410-420.

Tappata, M. (2009). Rockets and feathers: Understanding asymmetric pricing. Rand Journal of Economics, 40(4), 673-687.

Tasnádi, A. (1999). Two stage Bertrand-Edgeworth game. Economics Letters, 65(3), 353-358.

Valadkhani, A. (2013). Do petrol prices rise faster than they fall when the market shows significant disequilibria?. Energy Economics, 39, 66-80.

Verlinda, J. A. (2008). Do rockets rise faster and feathers fall slower in an atmosphere of local market power? Evidence from the retail gasoline market. Journal of Industrial Economics, 56(3), 581-612.

Yang, H., Ye, L. (2008). Search with learning: Understanding asymmetric price adjustments. Rand Journal of Economics, 39(2), 547-564. 